\title{
Radiation Crosslinking of a Mixture of Polyvinyle Alcohol Methacrylic acid and 2-Hydroxyethyle Methacrylate to Removal of Pollutant Dyes from its Aqueous Solution
}

\section{T. M. Mabrouk}

Radiation Research of Polymer Dept., National centre for radiation research and technology (NCRRT), P. O. Box; 29 Nasr City, Egypt.

\footnotetext{
TYDROGELS based on polyvinyle alcohol methacrylic acid/ 2-hydroxyethyle methacrylate [P(PVA-MAAc/HEMA)] were synthesized by gamma-radiation. The prepared hydrogels were characterized by infrared spectroscopy (FT-IR), scanning electron microscopy (SEM) and thermal gravimetric analysis (TGA). The results of the adsorption studies reveals the higher adsorption capacity of P(PVA-MAAc/ HEMA), hydrogel for the removal of methylene blue and xylenol orange dyes from aqueous solution.

Keywords: Polyvinyle alcohol, 2-hydroxyethyl methacrylate, methacrylic acid, dyes, $\gamma$-rays.
}

Dyes and pigments are widely used in the textiles, plastics, leather, food and cosmetic industry to colour products. The release of coloured waste water from these industries may present an eco-toxic hazard. Various techniques like precipitation, ion exchange, chemical oxidation, and adsorption have been used for the removal of toxic pollutant from waste water. Methylene blue and xylenol orange are selected as a model of pollutant dyes for evaluating the potential of P(PVA-MAAc/ HEMA) hydrogel to remove pollutant dyes from waste waters.

Superabsorbent hydrogels which can absorb very large amount of water and retain it, even under pressure this superabsorbent hydrogels are composed of homopolymers or copolymers. Irradiation processing is a successful technology for hydrogels preparation (Gu et al., 2007, Jin et al., 2009 and Lin and Metters, 2006). Ionizing irradiation technique offers unique advantages to prepare hydrogels over conventional method, especially for its approach to a clear environment (Chapiro and Claude, 1986 and Saraydin et al., 1997). 
Ionizing irradiation (gamma and electron beam) treatment is fast, does not induce a significant increase in temperature, requires minimal sample preparation and does not need any catalyst. In this study, P(PVA-MAAc/ HEMA) was studied for its potential use as adsorbent for removal of a pollutant dye from aqueous solution, factor affecting adsorption, such as, contact time, $\mathrm{pH}$, and temperature was evaluated. There are different techniques such as chemical oxidation, precipitation, ion exchange; adsorption has been used for the removal of pollutant from wastewater (Chiou and chuang, 2006, Salem and El-maazawi, 2000 and Stephenson and Sheldon, 1996). The first thing for an efficient adsorption process is the search for a low cost adsorbent with high adsorption capacity and second it should be biodegradable (Khattri and Singh, 2009). The constituents of adsorbents are mainly responsible for the removal of any particular pollutants from wastewater (Gao and Pedersen, 2005).

\section{Materials and methods}

\section{Materials}

All chemicals and reagents were of analytical grade, methacrylic acid (MMA) , 2-hydroxyethyle methacrylate (HEMA), Merck, Germany and Polyvinyl alcohol (PVA) were used as received, other chemicals, such as methylene blue , xylenol orange ,solvents, and other reagents were analytical grade, supplied by Algomhoria Company, Cairo, Egypt and used without further purification.

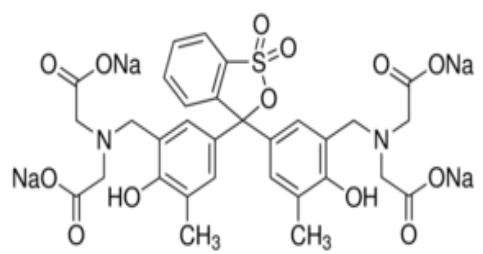

Fig. 1. Structure of xylenol orange tetrasodium salt (C31H28N2Na4O13S), $M W=760.6, \lambda \max =580 \mathrm{~nm}$.<smiles>CN(C)c1ccc2nc3ccc(=[N+](C)C)cc-3sc2c1</smiles>

Fig. 2. Structure of methylene blue $(\mathrm{C} 16 \mathrm{H} 18 \mathrm{~N} 3 \mathrm{SCl}), \mathrm{MW}=319.85, \lambda \max =663 \mathrm{~nm}$.

Egypt. J. Rad. Sci. Applic., Vol. 28, No. 1-2 (2015) 


\section{Preparation of hydrogels}

Different concentrations of PVA, 2, 4, $6 \mathrm{wt} \%$ are prepared by dissolving it in ionized water at $80^{\circ} \mathrm{C}$ with steering until complete solvation. A known volume of MAAc/ HEMA co-monomers of composition ratios (1:1) is dissolved in water is are subjected to different doses of gamma rays until become viscous and then added to different amounts of PVA with stirring. This mixture is placed in test tubes and then degassed by bubbling of pure nitrogen gas for $5 \mathrm{~min}$ and subjected to ${ }^{60} \mathrm{Co}$ Gamma irradiation. The prepared materials were washed several times with bi-distilled water and then dried in oven at $50^{\circ} \mathrm{C}$ for $24 \mathrm{~h}$. The product was then grounded and sieved to obtain the desired mesh size of $500 \mu \mathrm{m}$. The gelation (\%) of prepared hydrogel were soaked in distilled water to extract and soluble parts and dried in a vacuum oven at $50^{\circ} \mathrm{C}$. The gelation (\%) was calculated by the following equation:

$$
\text { Gelation }(\%)=\frac{\mathrm{w}_{e}}{\mathrm{~W}_{0}} \times 100
$$

Where, Wo is the wt of dried gel after irradiation, and We is the dried wt of the sample after extraction of soluble and unreacted species.

\section{Fourier transforms infrared spectroscopy (FT-IR)}

The IR spectrum was measured using ATI MATTFON [Genfis Series, Unicam, England] FTIR spectrometer. Each sample was thoroughly mixed with $\mathrm{KBr}$ as a matrix of the mixture was ground and then pressed to give a disc of standard diameter.

\section{Scanning electron microscopy (SEM)}

The morphology of the prepared material was studied using SEM. Samples were washed, dried and mounting on support and then made conductive with sputtered gold. The surface observations were made using JEOL JSM-5400 SEM.

\section{Thermal analysis}

The thermal properties of P(PVA-MAAc/ HEMA), hydrogels were investigated using Shimadzu-TGA-system of type TGA-50, Japan under nitrogen atmosphere $(20 \mathrm{ml} / \mathrm{min})$. The temperature ranged from ambient to $600^{\circ} \mathrm{C}$ at heating rate of $10^{\circ} \mathrm{C} / \mathrm{min}$. The primary TGA-thermograms were used to determine the rate of thermal decomposition reaction. 


\section{Swelling studies}

The clean dried hydrogel of pre-weight was soaked in bi-distilled water at room temperature for $24 \mathrm{~h}$. The hydrogel was removed and the excess water on the surface was removed by blotting quickly with filter paper and weighed. The swelling ratio was calculated as follows:

$$
\text { Swelling } \%=\frac{w_{\mathrm{g}}-\mathrm{w}_{\mathrm{d}}}{\mathrm{w}_{\mathrm{d}}} \times 100
$$

Where, Wd and Ws are the wt of dry and wet hydrogel, respectively.

\section{Results and Discussions}

\section{Characterization of prepared materials}

\section{Scanning Electron Microscopy (SEM)}

Fig. 1. show the surface morphological structure of P(PVA-AAc/ HEMA), hydrogel and as coarse surface with cavity and groovy structure possesses many largest pore size was obtained for P(PVA-MAAc/ HEMA) hydrogel.

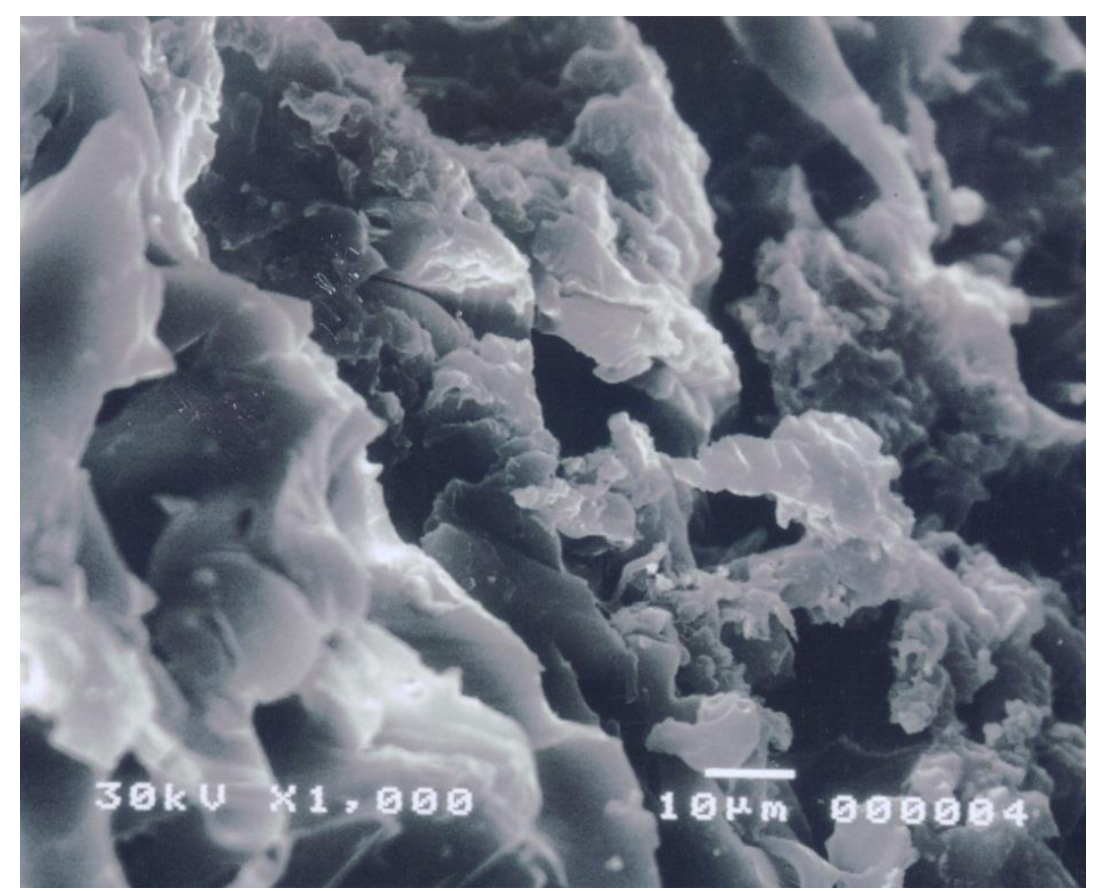

Fig. 3. Scanning electron microscope (SEM) of P(PVA-MAAc/ HEMA).

Egypt. J. Rad. Sci. Applic., Vol. 28, No. 1-2 (2015) 


\section{FTIR analysis}

Fig. 4. show the FTIR spectrum of P(PVA-MAAc/ HEMA), chains appear clearly broad band around $3400-3500 \mathrm{~cm}^{-1}$, corresponding to the hydroxyl $(\mathrm{OH})$. The peak at $1760 \mathrm{~cm}^{-1}$ corresponds to the carboxylic group of AAc. The bands at 1650 and $1780 \mathrm{~cm}^{-1}$ are attribute to the unsymmetrical and symmetrical stretching vibration of $\mathrm{C}=\mathrm{O}$ group in carboxylate anion, respectively. This was confirmed by another band at $1420 \mathrm{~cm}^{-1}$, which is related to the symmetric stretching mode of $\mathrm{C}=\mathrm{O}$ in the carboxylate groups (Liang and Liu, 2006).

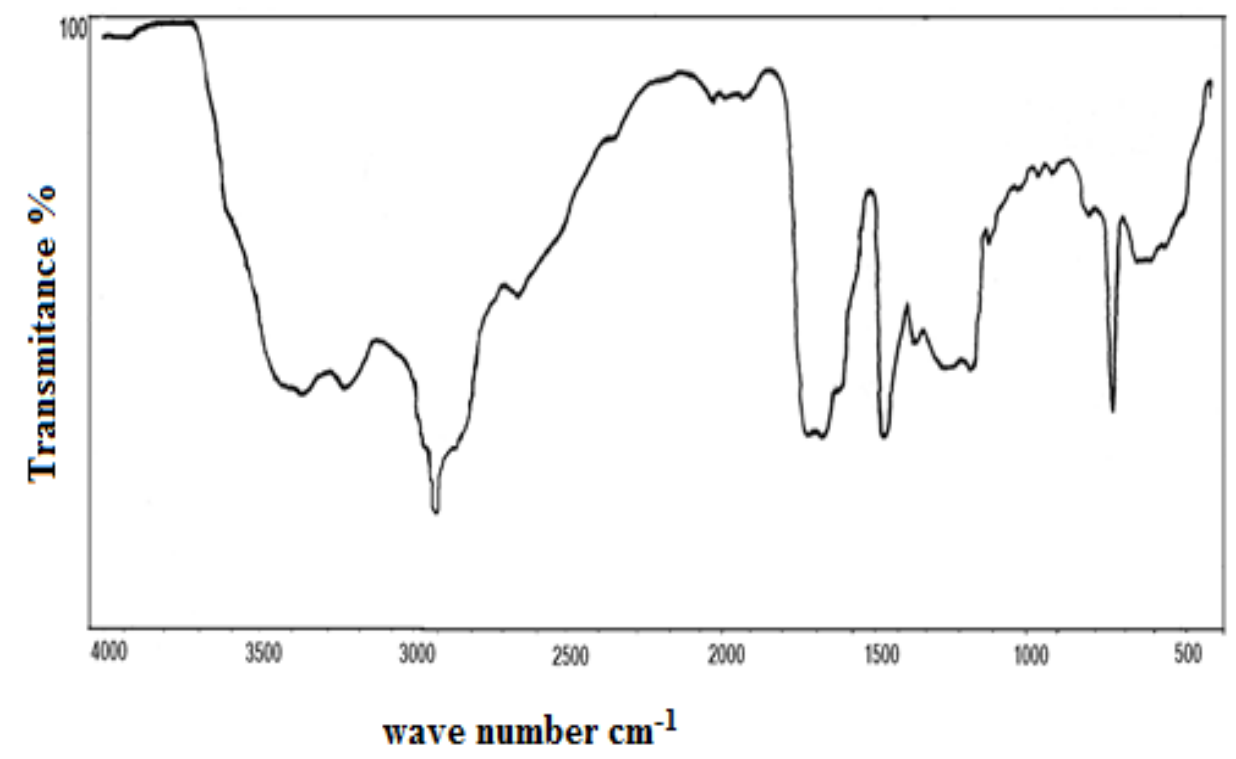

Fig. 4. FTIR of P(PVA-MAAc/ HEMA).

\section{Thermogravimetric analysis (TGA)}

TGA was employed to study the effect of thermal behaviour of the copolymer. The TGA of P(PVA-MAAc/ HEMA), hydrogel were studied, as shown in Fig. 5. The thermogram of P(PVA-MAAc/ HEMA), hydrogel shows three decomposition stages, the first decomposition stage within the range $50-240^{\circ} \mathrm{C}$ is attributed to the loss of physically adsorbed moisture. The second one within the interval $300-420^{\circ} \mathrm{C}$ has been ascribed to the dehydration and decarboxylation of the polymer which leads to the formation of inter- and intramolecular anhydride. The third decomposition stage within the range $390-550^{\circ} \mathrm{C}$ is a result of the degradation of the residual polymer. 


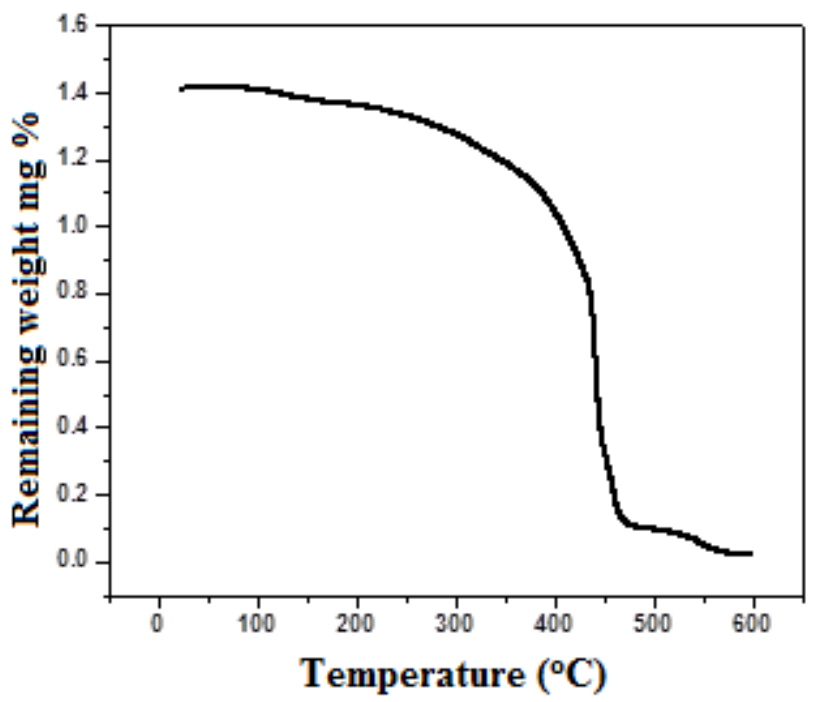

Fig. 5. Thermogravimetric analysis (TGA) of P(PVA-MAAc/ HEMA).

\section{Swelling behaviour}

The swelling of hydrogels occurs when the hydrogels are placed in contact with water or buffer solutions, the solution diffuses into the network and a volume phase transition occurs, resulting in an expansion of the hydrogel.

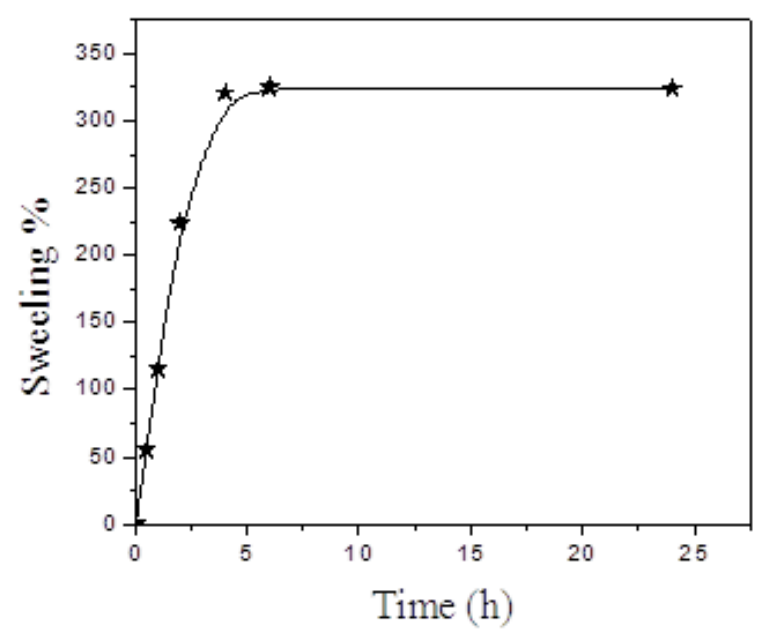

Fig. 6. Effect of time on the swelling \% of P(PVA-MAAc/ HEMA) at room temperature, composition of PVA: MAAc-HEMA (1:1).

Egypt. J. Rad. Sci. Applic., Vol. 28, No. 1-2 (2015) 
Fig. 6. show the swelling behaviour of P(PVA-MAAc/ HEMA) hydrogel, as a function of time. They indicate that the swelling (\%) increases with time, and reaches the maximum value after $3 \mathrm{~h}$. The swelling per-cent of hydrogels depends on the hydrophilicity of the polymer chains and the presence of more ionic groups in the polymer chains which are strongly solvated in aqueous medium. The equilibrium of swelling occurs when the values of the osmotic force driving the solvent into the network and of the elastic force of the stretched sub-chains become equal.

\section{Adsorption of the dyes}

Batch adsorption experiments were carried out at different temperatures between 20 and $50^{\circ} \mathrm{C}$ for the removal of different pollutant dyes from aqueous solutions by shaking $0.05 \mathrm{~g}$ of the adsorbent with $20.0 \mathrm{ml}$ of a required dye concentration at $\mathrm{pH}$ from (1-8) in a temperature controlled water bath shaker at $25^{\circ} \mathrm{C}$. At the end of the desired contact time the mixture was centrifuged and the residual concentration of each dye was measured. The concentrations of dye at equilibrium Ce were determined using UV-visible spectrometer at wave lengths 663 and 580nm for methylene blue and xylenol orange dyes, respectively. Therefore; $\mathrm{q}_{\mathrm{e}}$ values are calculated from the following equation:

$$
\mathrm{q}_{\mathrm{e}}(\mathrm{mg} / \mathrm{g})=\left(\mathrm{C}_{\mathrm{i}}-\mathrm{C}_{\mathrm{e}} / \mathrm{C}_{\mathrm{i}}\right) \mathrm{V} / \mathrm{m}
$$

Where, $\mathrm{q}_{\mathrm{e}}$ is the wt in (mg) of the dye adsorbed per gram (g) of dry adsorbent, $\mathrm{C}_{\mathrm{i}}$ and $\mathrm{C}_{\mathrm{e}}$ are the initial and equilibrium concentrations of dye adsorbate solution in $\mathrm{mg} / \mathrm{l}$ while, $\mathrm{V}$ is the volume of basic dye solution in $(\mathrm{ml})$ used in the batch adsorption process and $\mathrm{m}$ is the mass of adsorbent $(\mathrm{g} / \mathrm{l})$.

\section{Factors affecting on the adsorption of the dyes}

\section{Effect of time}

The effect of time can be seen from Fig. 7. for the dyes. It is clear that the extent of adsorption is rapid in the initial stages and becomes slow in later stages till saturation is allowed. The final dye concentration did not vary significantly after $1 \mathrm{~h}$ during adsorption process. This shows that equilibrium can be assumed to be achieved after $1 \mathrm{~h}$. It is basically due to saturation of the active site which does not allow further adsorption to take place. 


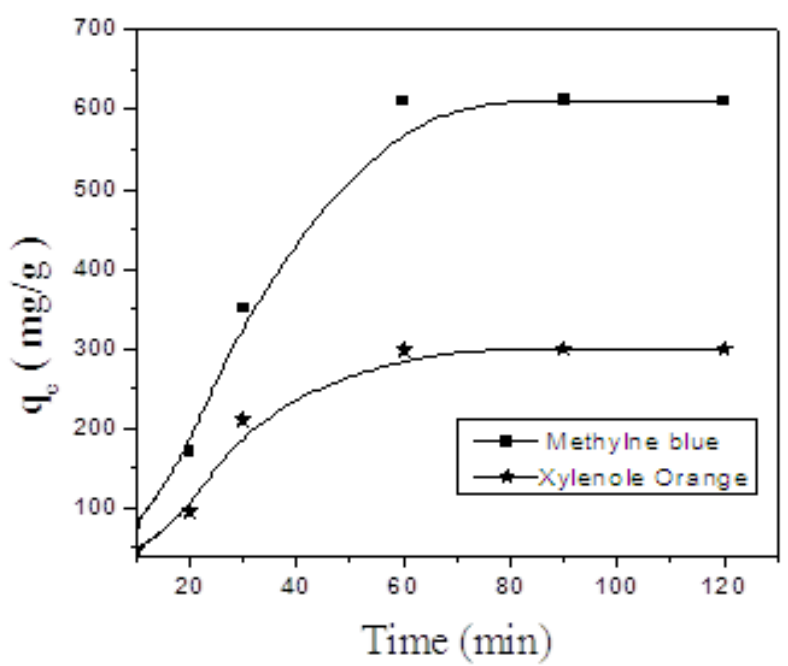

Fig. 7. Effect of time on the adsorption of dyes by P(PVA-MAAc/ HEMA) at room temperature, composition of PVA: MAAc-HEMA (1:1).

\section{Effect of $p H$ solution}

Fig. 8. show the effects of initial $\mathrm{pH}$ on dye solution of two dyes removal. The adsorption of dyes increase with increasing $\mathrm{pH}$ of dye solution and reached the maximum yield at $\mathrm{pH} 8$.

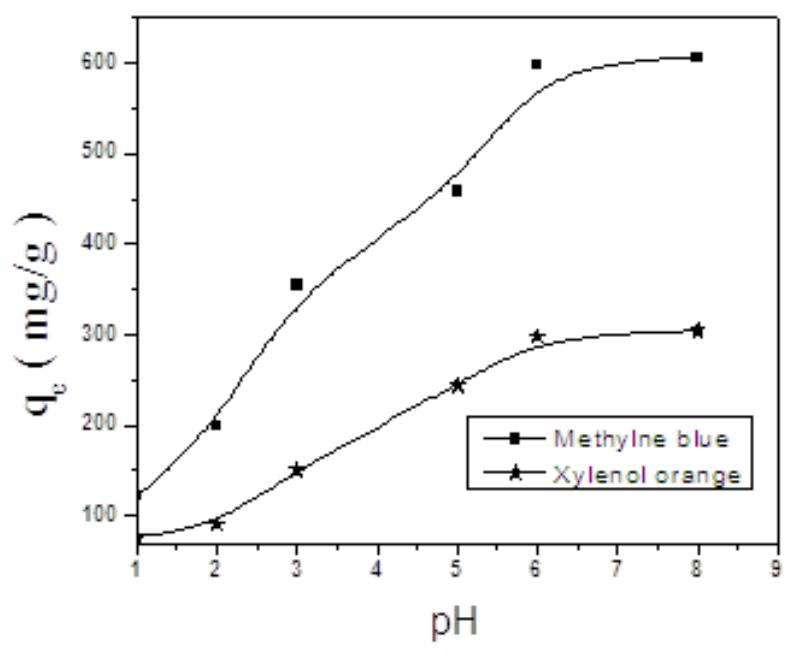

Fig. 8. Effect of $\mathrm{pH}$ on the adsorption of dyes by P(PVA-MAAc/ HEMA) at room temperature, composition of PVA: MAAc-HEMA (1:1) at time $1 \mathrm{~h}$.

Egypt. J. Rad. Sci. Applic., Vol. 28, No. 1-2 (2015) 
The adsorption of these positively charged dye groups on the adsorbent surface is primarily influenced by the surface charge on the adsorbent which in turn is influenced by the solution $\mathrm{pH}$. The result showed that availability of negatively charged groups at the adsorbent surface is necessary for the adsorption of pollutant dyes. Also, the removal efficiency was found to be highly dependent on the hydrogen ion concentration of solution.

\section{Effect of temperature}

The effect of temperature on adsorption of dye solution with initial concentration of $50 \mathrm{mg} / 1$ at temperatures $25,30,40 \& 50^{\circ} \mathrm{C}$ has been determined. The effect of temperature on the adsorption rate of methylene blue and xylenol orange been shown in the Fig. 9. as seen from the curves the rate of adsorption increase with increasing the temperatures for methylene blue and xylenol orange. This may be attributed to increase in the mobility of the large dye ion with temperature. An increasing number of molecules may also acquire sufficient energy to undergo an interaction with active sites at the surface. Furthermore, the temperature affects the adsorption rate by altering the molecular interactions and the solubility. The higher removal due to increasing temperature may be attributed to chemical reactions taking place between the phase's functional groups which are considered endothermic reactions (Hiroyuki et al., (1994).

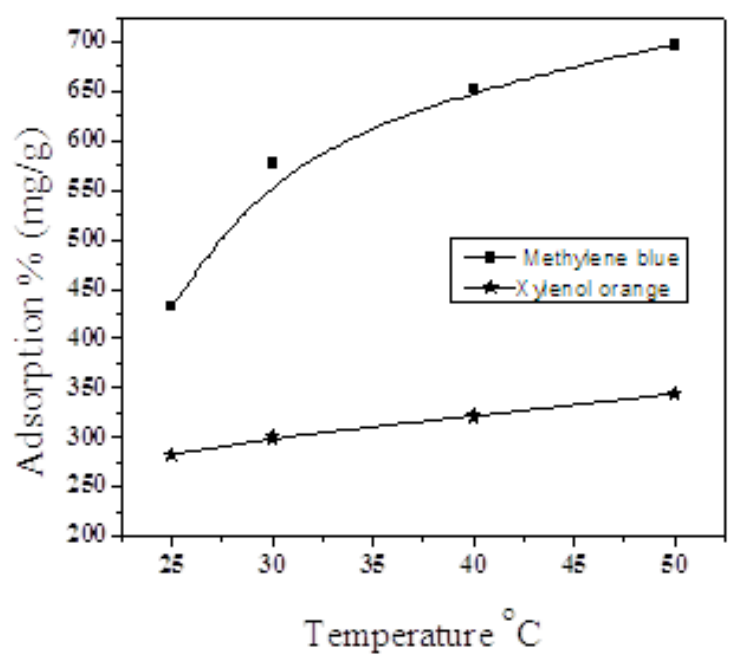

Fig. 9. Effect of temperature on the adsorption of methylene blue and xylenol orange on P(PVA-MAAc/ HEMA).

Egypt. J. Rad. Sci. Applic., Vol. 28, No. 1-2 (2015) 


\section{Conclusion}

Preparation of P(PVA-MAAc/ HEMA) by ionizing gamma radiation was studied and the characterization of prepared hydrogel by different analytical techniques such as IR, SEM and TGA were as investigated, also, studied of different factors affecting on the adsorption of methylene blue and xylenol orange obtained that the preparation of P(PVA-MAAc/ HEMA) can be used as good ion exchange for the removal of pollutant dyes from its solutions.

\section{References}

Lin, C. C. and Metters, A. T. (2006) Hydrogels in controlled release formulations: network design and modeling. Adv. Drug Deliv. Rev., $\mathbf{5 8}, 1379$.

Jin, L., Lu, P., You, H., Chen Q. and Dong, J. (2009) Vitamin B12 diffusion and binding in crosslinked poly(acrylic acid)s and poly(acrylic acidco-N-vinyl pyrrolidinone)s, Int. J. Pharm., 371, 82.

Gu, J., Xia F., Wub, Y., Qu, X., Yang, Z. and Jiang, L. (2007) Programmable delivery of hydrophilic drug using dually responsive hydrogel cages. J. Control. Releas., 117, 396.

El-Sherbiny, I. M. ( 2010) Enhanced pH-responsive carrier system based on alginate and chemically modified carboxymethyl chitosan for oral delivery of protein drugs Preparation and in-vitro assessment. Carbohyd. Polym., 80, 1125.

Chapiro, A. and Claude, L., (1986) Gel formation in the radiolysis of poly (Nvinylpyrrolidone) solution. Radiat. Phys. Chem., 28, 143.

Saraydin, D., Karadag, E. and Güven, O. (1997) Super water-retainer hydrogel: Crosslinked acrylamide/succinic acid copolymers. Polym. J. 29, 631.

Liang, R. and Liu, M. Z. (2006) Preparation and properties of a double-coated slow-release and water-retention urea fertilizer. J. Agr. Food Chem., 54, 1392.

Stephenson, R. J. and Sheldon, J. B. (1996) Coagulation and precipitation of mechanical pueffluent. 1. Removal of carbon and turbidity. Water Res., 30, 781.

Chiou, M. S. and Chuang, G. S. (2006) Competitive adsorption of dye metanil yellow in acidic solutions on chemically cross-linked chitosan beads. Chemosphere., 62, 731.

Egypt. J. Rad. Sci. Applic., Vol. 28, No. 1-2 (2015) 
Salem, I. A. and El-maazawi, M. (2000) Kinetics and mechanism of color removal of methylene blue with hydrogen peroxide catalyzed by some supported alumina surfaces. Chemosphere., 41, 1173.

Khattri, S. D. and Singh, M. K. (2009) Removal of malachite green from dye wastewater using neem sawdust by adsorption. J. Hazard. Mater., 167,1089 .

Gao, J. and Pedersen, J. A. (2005) Adsorption of sulfonamide antimicrobial agents to clay minerals. Environ. Sci. Technol., 39, 9509.

Hiroyuki, H., Fukuda, S., Okamoto, A. and Kataoka, T. (1994) Adsorption of acid dye cross-linked chitosan fibers-Equilibria. Chem. Egg. Sci., 48, 2267.

(Received: 01/03/2015;

accepted: 29/04/2015) 


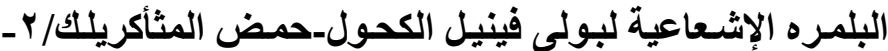 هياروكسى إثيل مثأكريلات لإزالة الصبغاتئات من محاليلها \\ طارق منصور محمد

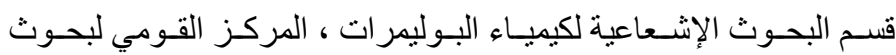

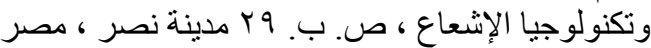

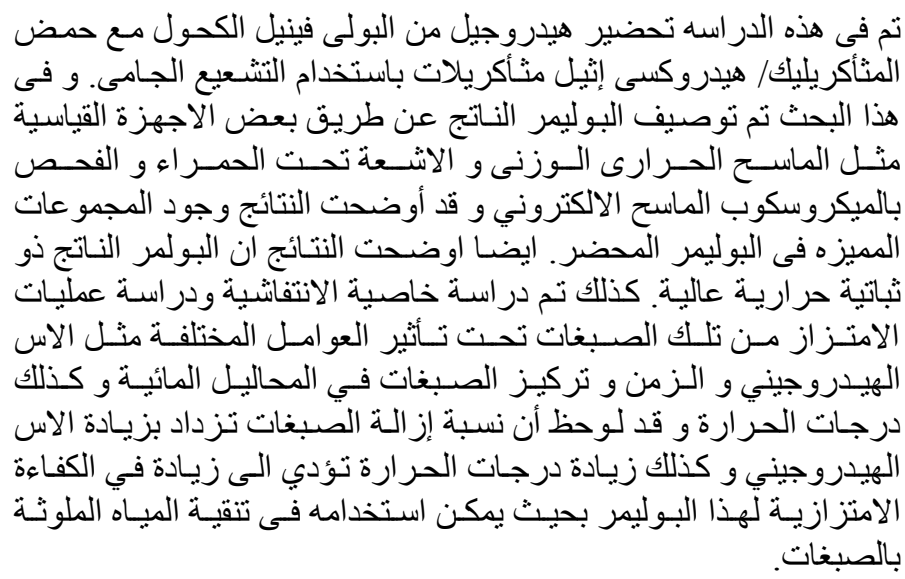

Egypt. J. Rad. Sci. Applic., Vol. 28, No. 1-2 (2015) 